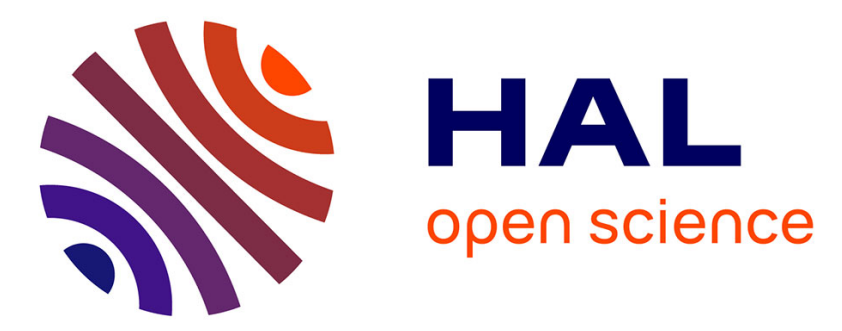

\title{
Comparison of residual NAPL source removal techniques in 3D metric scale experiments
}

Olivier Atteia, Florie Jousse, Grégory Cohen, Patrick Höhener

\section{To cite this version:}

Olivier Atteia, Florie Jousse, Grégory Cohen, Patrick Höhener. Comparison of residual NAPL source removal techniques in 3D metric scale experiments. Journal of Contaminant Hydrology, 2017, 202, pp.23-32. 10.1016/j.jconhyd.2017.04.006 . hal-01540354

\section{HAL Id: hal-01540354 \\ https://hal-amu.archives-ouvertes.fr/hal-01540354}

Submitted on 4 May 2018

HAL is a multi-disciplinary open access archive for the deposit and dissemination of scientific research documents, whether they are published or not. The documents may come from teaching and research institutions in France or abroad, or from public or private research centers.
L'archive ouverte pluridisciplinaire HAL, est destinée au dépôt et à la diffusion de documents scientifiques de niveau recherche, publiés ou non, émanant des établissements d'enseignement et de recherche français ou étrangers, des laboratoires publics ou privés. 


\title{
Comparison of residual NAPL source removal techniques in 3D metric scale experiments
}

\author{
O. Atteia ${ }^{a}$, , F. Jousse ${ }^{a}$, G. Cohen ${ }^{\mathrm{a}}$, P. Höhener ${ }^{\mathrm{b}}$ \\ ${ }^{a}$ Bordeaux INP - EA 4592 - ENSEGID, Institut Carnot/ISIFOR, 1 Allée F. Daguin, 33607 Pessac, France \\ ${ }^{\mathrm{b}}$ Aix Marseille Univ, CNRS UMR 7376, Laboratoire Chimie Environnement, 3 Place Victor Hugo, F-13331 Marseille, France
}

ARTICLE INFO

A B S T R A C T

This study compared four treatment techniques for the removal of a toluene/n-decane as NAPL (Non Aqueous Phase Liquid) phase mixture in identical 1 cubic meter tanks filled with different kind of sand. These four treatment techniques were: oxidation with persulfate, surfactant washing with Tween80®, sparging with air followed by ozone, and thermal treatment at $80^{\circ} \mathrm{C}$. The sources were made with three lenses of $26 \times 26 \times 6.5 \mathrm{~cm}$, one having a hydraulic conductivity similar to the whole tank and the two others a value 10 times smaller. The four techniques were studied after conditioning the tanks with tap water during approximately 80 days.

The persulfate treatment tests showed average removal of the contaminants but significant flux decrease if density effects are considered. Surfactant flushing did not show a highly significant increase of the flux of toluene but allowed an increased removal rate that could lead to an almost complete removal with longer treatment time. Sparging removed a significant amount but suggest that air was passing through localized gas channels and that the removal was stagnating after removing half of the contamination. Thermal treatment reached $100 \%$ removal after the target temperature of $80^{\circ} \mathrm{C}$ was kept during more than $10 \mathrm{~d}$.

The experiments emphasized the generation of a high-spatial heterogeneity in NAPL content. For all the treatments the overall removal was similar for both n-decane and toluene, suggesting that toluene was removed rapidly and n-decane more slowly in some zones, while no removal existed in other zones.

The oxidation and surfactant results were also analyzed for the relation between contaminant fluxes at the outlet and mass removal. For the first time, this approach clearly allowed the differentiation of the treatments. As a conclusion, experiments showed that the most important differences between the tested treatment techniques were not the global mass removal rates but the time required to reach $99 \%$ decrease in the contaminant fluxes, which were different for each technique.

\section{Introduction}

Remediation of NAPL (Non Aqueous Phase Liquid) sources in aquifers is known to be a difficult task (McCray et al., 2011). One of the critical steps is the choice of the technique. Facing a given contamination and geological context there is currently, to our knowledge, no theory that would allow choosing among different techniques. At field sites, it is not possible to compare the techniques on exactly the same contamination. We will present in the following the four most-used NAPL source remediation techniques (oxidation, surfactant injection, sparging, thermal remediation) and review comparative work on those techniques later on. In-situ contaminant oxidation is the first technique addressed here. Hood (2000) showed on a 3D PCE (Perchloroethene)/TCE (Trichloroethene) source emplaced at the Borden field site (Canada) that permanganate injection in front of the small source zone during $485 \mathrm{~d}$ was able to reduce more than $90 \%$ of the contaminant mass flux. It was however not possible to assess the amount of DNAPL (Dense NAPL) mass removed due to uncertainty in sampling. Thomson et al. (2008) showed on another emplaced source at Borden that oxidation of Polycyclic Aromatic Hydrocarbons (PAHs) had almost no effect on the long-term release of these products, although the added amount of oxidant should have removed all PAHs. In a vertical laboratory tank, Mackinnon and Thomson (2002) showed a significant removal (45\%) of PCE as NAPL by oxidation but the concentration at the pool outlet remained higher than $1 \mathrm{mg} \mathrm{L}^{-1}$. Schnarr et al. (1998) showed that permanganate was able to oxidize more than $90 \%$ of a PCE source at $8 \%$ residual saturation after adding approx. 6 pore volumes (PV) of a $10 \mathrm{~g} \mathrm{~L}^{-1}$ solution. However, using a naturally released source of $8 \mathrm{~L}$ of PCE, only $62 \%$ of the source could be removed with a similar addition of oxidant.

\footnotetext{
* Corresponding author.

Email address: olivier.atteia@ipb.fr (O. Atteia)
} 
Another well studied technique is surfactant flushing (Pennell et al., 1994). An efficient removal of a PCE source was shown by Ramsburg et al. (2005) with $99 \%$ of the initial PCE removed in $270 \mathrm{~d}$ of Tween80® flushing. Page et al. (2007) showed a significant removal of PCE (70\%) in experimental vertical tanks. However, this PCE removal did not lead to a decrease of concentrations in water due to an enhanced area of contact between NAPL and water. Londergan et al. (2001) compared several sites where surfactants were used and showed that an increasing amount of surfactant used, varying from 1 to $14 \mathrm{PV}$ (pore volume), did not directly increase the efficiency of the reduction in NAPL mass. The maximum reduction obtained was $98 \%$ at a controlled site. Oostrom et al. (1999) showed in a layered 2D vertical tank that the injection of approximately $65 \mathrm{PV}$ of alternating water and surfactant reached only a removal of $60 \%$ of the injected NAPL TCE, most of the remaining one being in low permeability layers.

A third technique often applied is air sparging, which consists in injecting air flow through the soil. Some sparging studies were done on 2D vertical laboratory tanks to explore the preferential gas pathways, which significantly reduce the treatment efficiency (Rogers and Ong, 2000). At the column scale this effect has also been clearly demonstrated through X-ray scanning (Chen et al., 1996) and has been modeled successfully through a semi-empirical approach including a frequency of air tubes (Braida and Ong, 2001). It is however still not possible to predict the sparging efficiency in porous media for a given air flow rate.

The last technique chosen here is thermal treatment, which works by increasing the overall temperature of the soil. It is usually promoted by electrical resistivity heating. Few laboratory or tank scale studies have been conducted. In an unsaturated column a fast and complete removal was obtained through heating (Kawala and Atamańczuk, 1998). In saturated columns the results also showed a fast and complete removal of PCE at $90{ }^{\circ} \mathrm{C}$ heating (Burghardt and Kueper, 2008). At the tank scale, Heron et al. (1998) showed a removal higher than $99 \%$ of dissolved TCE (at saturation) in a $1 \times 0.5 \times 0.1 \mathrm{~m}$ tank.

In the previous cited experiments there were large differences in the removal efficiency. The variation in efficiency is mainly linked to the presence of heterogeneities in hydraulic conductivities that tend to deviate the flow of the treatment fluid towards the most permeable zones. During the source evolution the contaminants are first present over the bulk volume, and as they are preferentially leached out from the most permeable zone they finally remain in the least permeable ones. As an example, Taylor et al. (2001) showed that the removals by surfactant dissolution obtained in column experiments were much higher than in 2D tank experiments.

As it is presently not possible to predict the efficiency of source removal techniques in presence of heterogeneity, it is of major importance to compare the different techniques within the same medium presenting controlled heterogeneity. At the field scale, there have been some comparisons (Cape Canaveral, or Dover, USA (Difilippo and Brusseau, 2008)) but it was difficult to draw general conclusions because the sources were different. Large size tests were done at Hill Air Force Base (USA) on isolated cells under controlled conditions, but the results showed that the removal efficiency was tightly linked to the soil heterogeneity, limiting a strict comparison of the treatment techniques (McCray et al., 2011). Similarly, Brooks et al. (2008) compared remedial efficiency at two sites, showing a 90\% reduction flux of TCE at both sites, but a significant increase of DCE flux in presence of biodegradation downgradient the source zone. Barnier et al. (2013) compared two pilot treatments (In Situ Chemical Reduction (ISCR) and Enhanced bioremediation (ENA)) on two sources at the same site, showing similar increase in degradation rate (increase by a factor of 1.5 to 2 ) and dissolution rate (increase by a factor of 2.5 to 3 ). However, none of these two papers could strictly compare the techniques, as it was not conducted on the same source zones. At the tank scale, the only study presenting comparisons that we found is the one of Conrad et al. (2002). In that study, a $2 \mathrm{D}$ vertical experiment was conducted with emplaced NAPL pools, and it was shown that surfactant flushing was more efficient than oxidation with permanganate. It was not possible to find any comparison of more than two techniques, and particularly not with conditions close to field ones, i.e. in 3D tanks.
Therefore, the global objective of the present paper is to provide a detailed comparison of the most widely used techniques for residual NAPL removal in order to assess their comparative sensitivity to heterogeneity. Treatment techniques were chosen among the most common ones: oxidation, surfactant flushing, sparging and thermal treatment. The treatments were previously optimized at the column scale (Jousse et al., 2016). The tested techniques gave remediation efficiency higher than $90 \%$ at the column scale, it is thus interesting to know the efficiency in a 3D medium and to understand the origin of a potential decrease in this efficiency.

The specific objectives of this paper are as follows:

1) Compare the 4 treatment techniques with the same geometry, including defined heterogeneity

2) Analyze the role of the treatment techniques on the spatial distribution of the remaining NAPL

3) Provide a conceptual model that allows comparison of techniques and origin of the observed differences.

\section{Material and methods}

The main objective was to compare the remediation techniques in presence of heterogeneity in the porous media. Due to the different behavior of the four techniques it was necessary to work on three dimensional objects. As heterogeneity of the medium was suspected to affect the results it was necessary to have lenses of a significant size to allow sampling of such heterogeneous medium. The minimum size of the lenses was a few decimeter, leading to a size of the tanks in the order of one cubic meter.

\subsection{Experimental tanks: global description and set up}

We built four identical tanks of $0.95 \times 1.1 \times 0.8 \mathrm{~m}(\mathrm{w}, \mathrm{l}, \mathrm{h})$ outdoor and protected them with a shelter. They were mostly filled with sand having a hydraulic conductivity of $4.10^{-4} \mathrm{~m} \mathrm{~s}^{-1}$. Three lenses of contaminated sand $(26 \times 26 \times 6.5 \mathrm{~cm})$ were included in the medium (Fig. 1). The source located in the middle of the tank had the same hydraulic conductivity as the rest of the tank. The bottom and top sources were made of more fine-grained sand which had a hydraulic conductivity of $3.10^{-5} \mathrm{~m} \mathrm{~s}^{-1}$.

We made all sources with the same composition: a 1:1 volumic n-decane $\left(\mathrm{C}_{10} \mathrm{H}_{22}, 99 \%\right.$, Fisher $)$ and toluene $\left(\mathrm{C}_{7} \mathrm{H}_{8}, 99 \%\right.$, Fisher $)$ mixture at $10 \%$ saturation. The contaminated sand was prepared by adding the equivalent of $20 \%$ saturation of water to the dry sand in a rectangular box and then the required amount of contaminants to reach $10 \%$ saturation and then completed with water. We conducted the operations in less than 2 min with cold contaminant $\left(4^{\circ} \mathrm{C}\right)$ liquids to avoid volatilization as much as possible. The boxes were then sealed and rapidly positioned in the tanks. We also applied a blank procedure to verify that the mixture reached the target concentrations. The lenses with low hydraulic conductivity sand contained 11.6 and $9.75 \mathrm{~g} \mathrm{~kg}^{-1}$ of toluene and n-decane, respectively, while these mass concentrations were 10.8 and $9.1 \mathrm{~g} \mathrm{~kg}^{-1}$ for the lens with high hydraulic conductivity medium. These results were confirmed by re-analysis of the contaminated lenses showing the same values.

After placing the injection (I) and pumping (O) wells which were entirely screened, the tanks were progressively filled with sand keeping a water level a few $\mathrm{cm}$ above the sand top in order to tightly pack the sand. The previously prepared contaminated lenses were set up on top of the sand layer, surrounded by non-contaminated sand. Then, the surrounding metal box was quickly removed and sand was added above the lenses. Finally the tanks were sealed with $10 \mathrm{~cm}$ of bentonite clay on top to insure the absence of contaminant volatilization. The pore volumes of the tanks, measured during water addition, were close to $247 \mathrm{~L}$.

As gases might be emitted in sparging and thermal treatments tanks, the top part of these tanks was specifically equipped with a coarse sand layer between the tank sand and the top clay layer. In this coarse sand screened Teflon tubing ending outside the clay was inserted, in order to sample the gas phase. In the 

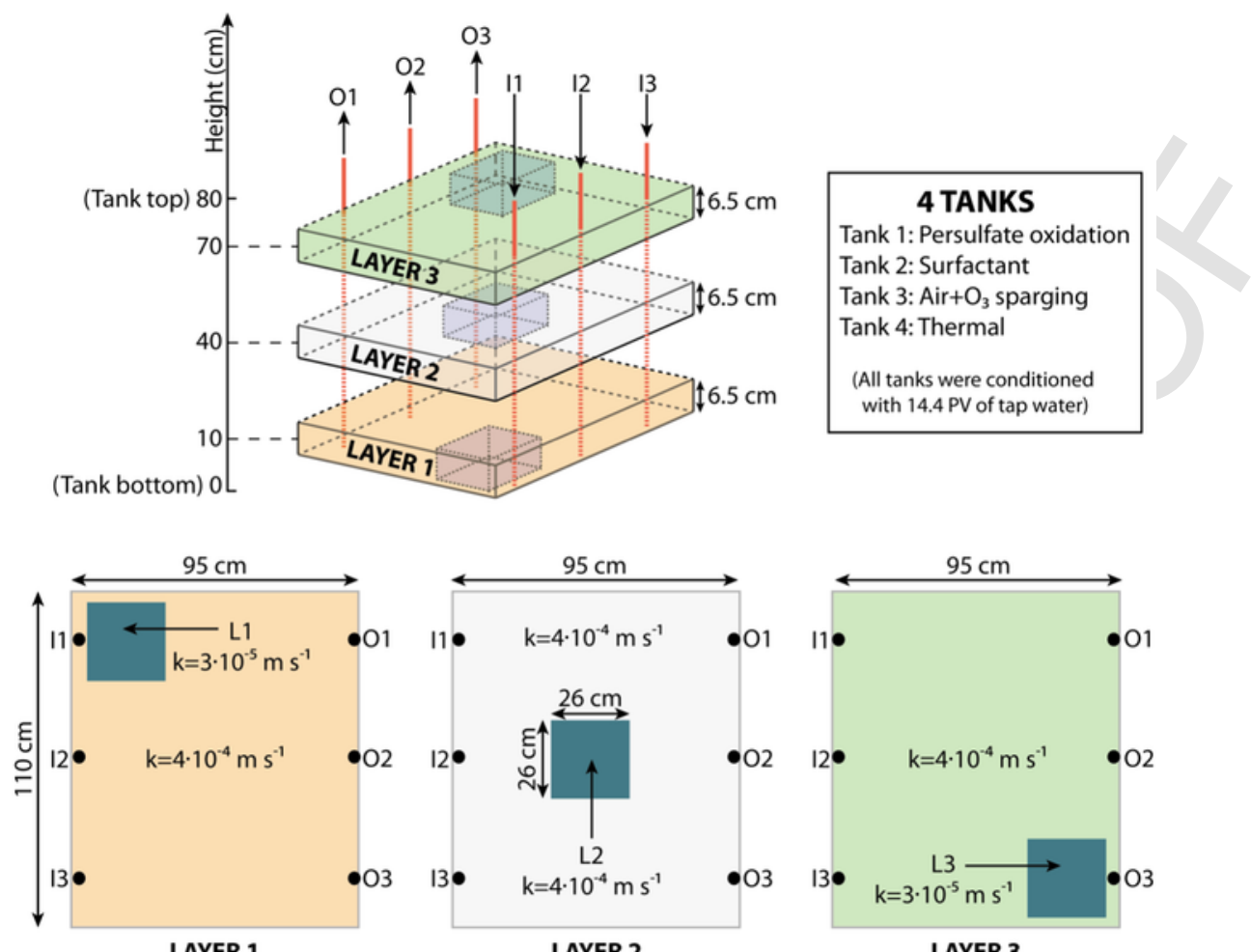

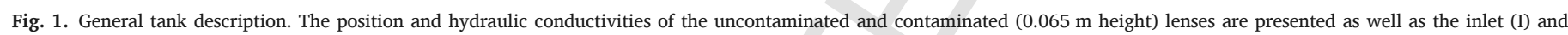

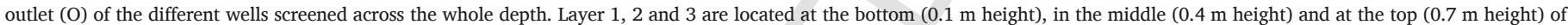
the tank, respectively.

sparging treatment tank, the same type of tube was placed at the bottom of the tank to inject air. In the thermal treatment tank, a copper tube allowing hot water recirculation was inserted at the bottom of the tank.

\subsection{Tank conditioning}

During the first period, we conditioned the four tanks during approximately $80 \mathrm{~d}$ with tap water $(\mathrm{pH} \mathrm{7.3,} \mathrm{EC} 480 \mu \mathrm{S} / \mathrm{cm})$ injected in the three injection wells (I) and pumped out on the three wells from the other side $(\mathrm{O})$. The total injection pumping rate was $45 \mathrm{~L} \mathrm{~d}^{-1} \mathrm{di}$ vided equally in the three wells $\left(15 \mathrm{~L} \mathrm{~d}^{-1}\right.$ per well) by using a peristaltic pump. This led to an amount of $0.18 \mathrm{PV} \mathrm{d}^{-1}$ or a pore velocity of $17 \mathrm{~cm} \mathrm{~d}^{-1}$ which is in the range of velocities found during source treatment (Difilippo and Brusseau, 2008).

\subsection{Specific tank treatment}

After the conditioning period, a specific treatment was applied to each tank. The four tanks were used as follows: (1) persulfate, (2) surfactant (Tween80®), (3) sparging with air followed by ozone and (4) low temperature $\left(80^{\circ} \mathrm{C}\right)$ thermal treatment. These treatments are described hereafter.

\subsubsection{Tank 1: persulfate oxidation}

After conditioning, sodium persulfate $\left(\mathrm{Na}_{2} \mathrm{~S}_{2} \mathrm{O}_{8}, 98 \%\right.$, Fisher) was added in three time phases in order to test different procedures to face the density effects (Fig. 2). Indeed, it was shown in previous studies that a high concentration of persulfate was more efficient for pollutant removal (Jousse et al., 2016). Persulfate was activated with a $\mathrm{Fe}(\mathrm{II})$ $\left(\mathrm{FeSO}_{4}, 7 \mathrm{H}_{2} \mathrm{O}, 98 \%\right.$, Fisher) solution. The three time phases are described hereafter:

- During phase 1 , persulfate $\left(50 \mathrm{gL}^{-1}\right)$ activated with $\mathrm{Fe}(\mathrm{II})$ at $2.5 \mathrm{~g} \mathrm{~L}^{-1}$ was added only in well $\mathrm{I} 1$, the one close to the bottom lens. Fifteen liters of solution were added over the total height of the well in one day. Then the tank rested with no flow during one week to leave sufficient time for the reaction to occur. Then, water was again flushed during $30 \mathrm{~d}$.

- During phase 2 , the tank was entirely flushed $(\approx 1 \mathrm{PV})$ with a solution of $5 \mathrm{~g} \mathrm{~L}^{-1}$ of persulfate with $0.25 \mathrm{~g} \mathrm{~L}^{-1} \mathrm{Fe}(\mathrm{II})$ at high flow rate $\left(200 \mathrm{~L} \mathrm{~d}^{-1}\right)$ to limit density effects. The tank rested during one week and was then washed with water during $15 \mathrm{~d}$.

- During phase 3 , a solution of $50 \mathrm{~g} \mathrm{~L}^{-1}$ of $\mathrm{NaCl}$ was added to the tank $(\approx 1 \mathrm{PV})$ at a high flow rate $\left(200 \mathrm{~L} \mathrm{~d}^{-1}\right)$ to fill the tank with that solution. Then, a $50 \mathrm{~g} \mathrm{~L}^{-1}$ persulfate solution with $2.5 \mathrm{~g} \mathrm{~L}^{-1} \mathrm{Fe}(\mathrm{II})$ was injected at a $45 \mathrm{~L} \mathrm{~d}^{-1}$ rate during $2 \mathrm{~d}$. The tank rested for one week and was washed with water for another week.

\subsubsection{Tank 2: surfactant}

The used surfactant was Tween $80 \AA$ ( $98 \%$, Sigma Aldrich). The surfactant injection was conducted at a discharge flow rate varying between 60 and $180 \mathrm{~L} \mathrm{~d}^{-1}$ during $21 \mathrm{~d}$ to a total volume of $2160 \mathrm{~L}$ ( $\approx 8 \mathrm{PV}$ ). The used Tween80® concentration was equal to $150 \mathrm{mg} \mathrm{L}^{-1}$ (10 times the critical micellar concentration). Previous experiments showed that the solubility of toluene was enhanced by a factor of 2.5 in Tween80® (Jousse et al., 2016).

\subsubsection{Tank 3: sparging with air and ozone}

Sparged air was pumped from the atmosphere and ozone was produced with an ozone generator (BMT 802, BMT Messtechnik GmbH). Air was sparged during two weeks at a flow rate of $600 \mathrm{~L} \mathrm{~d}^{-1}$. After this period ozone was added to air keeping the same flow rate. The rate of ozone injection was equal to $15 \mathrm{~g} \mathrm{~d}^{-1}$. This air + ozone injection lasted $10 \mathrm{~d}$.

\subsubsection{Tank 4: thermal treatment}

The thermal treatment was simply conducted by circulating hot water kept between 80 and $90{ }^{\circ} \mathrm{C}$ in the bottom of the tank during $25 \mathrm{~d}$. The temperature regulation was approximate due to the volume used, the long period and the fact that the tanks were located outside. 


\begin{tabular}{|c|c|c|c|}
\hline $\begin{array}{l}\text { Tank 1: } \\
\text { oxidation }\end{array}$ & $\begin{array}{c}\text { Tank 2: } \\
\text { surfactant }\end{array}$ & $\begin{array}{c}\text { Tank 3: } \\
\text { sparging }\end{array}$ & $\begin{array}{l}\text { Tank 4: } \\
\text { thermal }\end{array}$ \\
\hline \multicolumn{4}{|c|}{$\begin{array}{l}\text { Tank conditioning ( } 80 \mathrm{~d}) \\
\text { (14.4 PV of tap water) }\end{array}$} \\
\hline $\begin{array}{c}\text { Phase } 1 \text { (38 d): } \\
15 \mathrm{~L} \text { of } 50 \mathrm{~g} \mathrm{~L}^{-1} \mathrm{~S}_{2} \mathrm{O}_{8}^{2-} \text { solution (1 d) } \\
7 \mathrm{~d} \text { without flow } \\
30 \mathrm{~d} \text { water flow } \\
\text { Phase } 2 \text { (21 d): } \\
1 \mathrm{PV} \text { of } 5 \mathrm{~g} \mathrm{~L}^{-1} \mathrm{~S}_{2} \mathrm{O}_{8}^{2-} \text { in all wells }(1.2 \mathrm{~h}) \\
7 \mathrm{~d}_{\text {without flow }} \\
14 \mathrm{~d} \text { water flow } \\
\text { Phase } 3 \text { (16 d): } \\
1 \mathrm{PV} \text { of } 200 \mathrm{~g} \mathrm{~L}^{-1} \mathrm{NaCl} \text { solution }(1.2 \mathrm{~h}) \\
45 \mathrm{~L} \text { of } 50 \mathrm{~g} \mathrm{~L}^{-1} \mathrm{~S}_{2} \mathrm{O}_{8}^{2-} \text { on the top }(2 \mathrm{~d}) \\
7 \mathrm{~d}^{2} \text { without flow } \\
7 \mathrm{~d}^{2} \text { water flow }\end{array}$ & 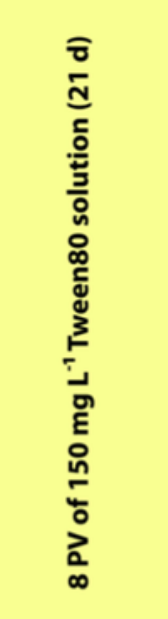 & 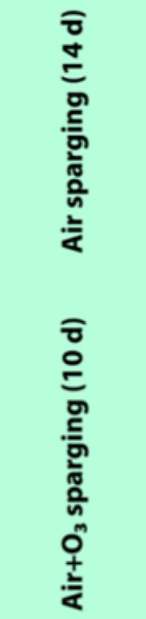 & 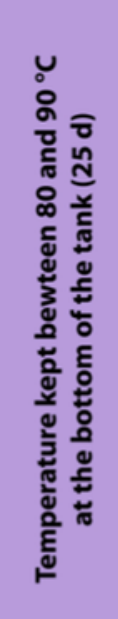 \\
\hline \multicolumn{4}{|c|}{ Tank dismounting } \\
\hline
\end{tabular}

Fig. 2. Treatment procedure for the four tanks.

vials were shaken during heating. Then, $500 \mu \mathrm{L}$ of the headspace vial gas phase was automatically sampled and injected in GC-FID. In presence of surfactant in the solution (Tank 2, surfactant), the micelles were first destabilized by adding ethanol in the headspace vials. The extraction yield was determined previously and was close to 95\%.

At the end of the experiments, the porous media was extracted from tanks for contaminants analysis. The solid (sand) aliquots were sampled in the three layers that contained the contaminated lenses. In each layer 9 samples were taken on a regular grid, each sample consisting of a mixture of 3 sub-samples ( $3 \mathrm{~mL}$ of sand) taken a few centimeters apart from each other. In addition, in the contaminated low hydraulic conductivity lenses 9 samples were taken in a regular grid, again made of 3 sub-samples. In the contaminated lens of layer 2, only one sample (with 3 sub-samples) was taken as its hydraulic conductivity was the same of the rest of its layer, and we first considered that no product would remain in that lens.

\subsection{Analytical procedures}

In order to determine contamination removal during the conditioning period, the four specific treatment techniques as well as after the treatment, contaminant concentrations were monitored. All samples were analyzed with a GC-FID (CP 3800, VARIAN, France) equipped with a low polarity capillary column (Rxi-5silMS, $30 \mathrm{~m}, 0.25 \mathrm{~mm}, 0.25 \mu \mathrm{m}$, RESTEK, USA). The same chromatographic protocol as described in Cohen et al. (2016a,b) was applied for all samples. External calibration was used for gas and liquid phase analysis. Internal calibration was used for solid samples analysis. The detection limits were equal to $20 \mu \mathrm{g} \mathrm{L}^{-1}$ in water and $50 \mathrm{mg} \mathrm{kg}^{-1}$ in solid. Depending on the treatment period, contaminant was monitored in different phases (solid, liquid and gas):

- Gas phase (Tank 3, sparging) was collected in Tedlar bags (Fisher Scientific). An aliquot of $500 \mu \mathrm{L}$ was taken from the Tedlar bag with a manual syringe and directly injected in GC-FID (Cohen et al., 2016a,b).

- Liquid (aqueous) phase sampled in all tanks during conditioning part and Tank 1, 2 and 4 during specific treatment technique, was collected in headspace vials (Barnier et al., 2013). The headspace vials were heated at $40{ }^{\circ} \mathrm{C}$ during $20 \mathrm{~min}$. In order to achieve homogeneous heating, the headspace
- Solid (sand) samples taken from all tanks during dismounting period were shaken with n-hexane during $24 \mathrm{~h}$ (Brooks et al., 2008). After decantation, $2 \mathrm{~mL}$ of the supernatant were sampled in vials and two microliters of n-octane were added into the vial as internal standard. Then, $1 \mu \mathrm{L}$ of the liquid solution was automatically sampled and injected in GC-FID.

\section{Results}

\subsection{Conditioning period}

The conditioning period lasted approximately 80 days for each tank; the tanks were started at two different times: tanks 1 and 2 first and 20 days later tanks 3 and 4 . The concentrations of toluene sampled at the tanks outlet, show important and rapid temporal variations (Fig. S1) as shown by other authors for the early cleaning phase of an emplaced NAPL source (Rivett and Feenstra, 2005). Along the period, it appeared that some high concentration peaks are correlated between the tanks with a similar temporal trend. A time series and correlation analysis showed that these variations are not correlated to temperature variations or explained by analytical biases. However, the concentrations are decreasing in all tanks after approximately 70 days.

The total amounts of toluene removed from the tanks during the conditioning period are given in Table 1 . It can be noticed that despite important temporal variations (see Fig. S1) the total amounts removed from the tanks 2-4 show differences smaller than $3 \mathrm{~g}$, indicating a similar behavior during dissolution, tank one showing a dissolution higher by $8 \mathrm{~g}$. Although the total amounts are close to the amount present in one lens (56 $\mathrm{g}$ of toluene), it was not possible to know, after the conditioning period, if this amount corresponded only to the most permeable lens. The concentrations of $\mathrm{n}$-decane in the pumping wells were negligible. 
Table 1

Total amounts of toluene removed from the tanks during the conditioning period (in $g$ and percentage of initial). The error on the mean is calculated as the standard deviation of concentrations divided by the square root of the sample number.

\begin{tabular}{lllll}
\hline Tank & 1 & 2 & 3 & 4 \\
\hline $\begin{array}{l}\text { Amount } \\
\text { g) and }\end{array}$ & $64.9 \pm 0.6$ & $57.8 \pm 0.6$ & $54.4 \pm 0.5$ & $57.1 \pm 0.6$ \\
$\begin{array}{l}\text { percentage } \\
\text { of toluene } \\
\text { removed }\end{array}$ & $37.5 \%$ & $33.4 \%$ & $31.4 \%$ & $33 \%$ \\
\hline
\end{tabular}

\subsection{Treatment phase}

\subsubsection{Persulfate oxidation}

The concentrations of sulfate and persulfate were monitored at the outlet of tank 1 at specific depth in the pumping wells. During time phase 1 (injection in one well) the average persulfate concentrations at the outflowing wells were close to $0.4 \mathrm{~g} \mathrm{~L}^{-1}\left(0.2 \mathrm{mmol} \mathrm{L}^{-1}\right)$ while the injection was conducted at a concentration of $50 \mathrm{~g} \mathrm{~L}^{-1}$, which should have led to an average concentration of $16.67 \mathrm{~g} \mathrm{~L}^{-1}$ due to dilution (one well out of three). Sulfate concentrations were slightly higher than persulfate $\left(0.5-0.6 \mathrm{~g} \mathrm{~L}^{-1}\right.$ or $\left.5.5-6 \mathrm{mmol} \mathrm{L}^{-1}\right)$, but the sum of both species was much smaller than the injected concentration (Fig. S2). Mass balance calculation showed that only approximately $12 \%$ of the injected amount of persulfate was recovered as sulfate or persulfate. The remaining $88 \%$ thus remained in the tank, certainly due to density effects. Indeed, very high concentrations (5 to $35 \mathrm{~g} \mathrm{~L}^{-1}$ ) of persulfate were recovered at the bottom of the tank at the end of the treatment. During that period, there was still toluene at the outlet of the tank at concentrations varying from 2.5 to $5 \mathrm{mg} \mathrm{L}^{-1}$ (0.027 to $0.054 \mathrm{mmol} \mathrm{L}^{-1}$ ), with no clear temporal trend. The decrease of 15 to $17.5 \mathrm{mg} \mathrm{L}^{-1}$ ( 0.16 to $0.19 \mathrm{mmol} \mathrm{L}^{-1}$ ) of toluene would lead to the stoichiometric production of 2.9 to $3.4 \mathrm{mmol} \mathrm{L}^{-1}$ of sulfate from persulfate. The observed increase of sulfate of $5.7 \mathrm{mmol} \mathrm{L}^{-1}$ is approximately twice higher than toluene decrease, and therefore it can be concluded that persulfate is also reduced to sulfate due to the addition of iron.

During time phase 2 (injection of $5 \mathrm{~g} \mathrm{~L}^{-1}$ over the whole tank), the concentrations of persulfate and sulfate were more stable, showing a steady decrease, with similar concentrations for persulfate and sulfate (Fig. S3). The sum of the two species (varying between 20 and $30 \mathrm{mmol} \mathrm{L}^{-1}$ from day 10 to day 15 ) was close to the injected concentration $\left(25 \mathrm{mmol} \mathrm{L}^{-1}\right)$ showing no loss as a consequence of density effect. However, the concentrations showed absence of a pulse, contrary to the input, suggesting that there were significant heterogeneities that lead to mixing downgradient the lenses. As for phase 1 , due to the stoichiometry of the reaction, most of the sulfate produced could not originate from hydrocarbon oxidation only.

During phase 3 (injection of $50 \mathrm{~g} \mathrm{~L}^{-1}$ over the top $20 \mathrm{~cm}$ ), the concentrations of persulfate measured at the outlet also showed a steady decreasing curve, from 6 to $4 \mathrm{mmol} \mathrm{L}^{-1}$, values lower than during time phase 2 (Fig. S4). The concentrations were similar (less than $0.5 \mathrm{mmol} \mathrm{L}^{-1}$ difference) at different depths, although the persulfate was injected only in the top layer. It seems that despite all precautions taken the density effect led to a mixing of the solution from the top layers with the bottom ones, that may also happen in real world. Mass balance analysis showed that approximately $25 \%$ of the persulfate injected during phase 3 was recovered at the outflow.

After the last persulfate injection the concentrations of toluene at the outflow were very low, about 0.1 to $0.2 \mathrm{mg} \mathrm{L}^{-1}$ (Fig. 3), in the lower part of the tank where persulfate accumulated while it remained at a level of $1-2 \mathrm{mg} \mathrm{L}^{-1}$ in the medium and upper parts.

After dismounting the tank, the contaminated lenses were analyzed in detail for toluene and n-decane content (Fig. 4). For toluene the average removal (54\%) was similar for all lenses, which may result from higher water washing in the mid lens and significant oxidation in the less permeable lenses, which were specifically targeted in phases 1 and 3 . In the less permeable lenses, the removals were highly variable changing from 0 to $90 \%$ across $9 \mathrm{~cm}$ distance.

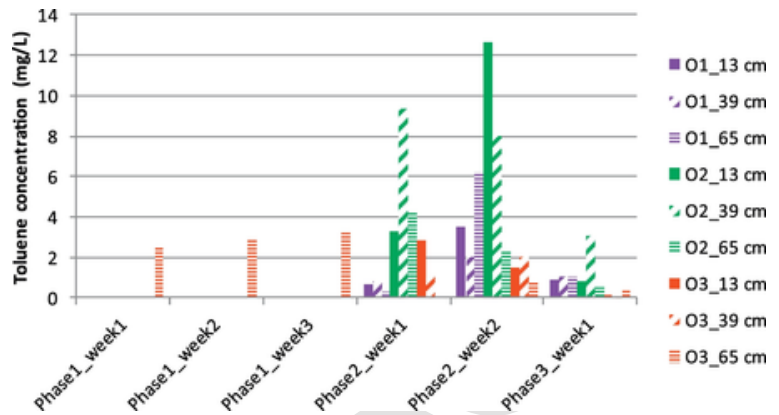

Fig. 3. Temporal evolution of toluene concentrations $\left(\mathrm{mg} \mathrm{L}^{-1}\right)$ at the outlet of the persulfate tank for $\mathrm{O} 1, \mathrm{O} 2$ and $\mathrm{O} 3$ wells at three depths $(13,39$ and $65 \mathrm{~cm})$, although all wells were pumped, only specific depths were sampled at some periods. Bars show the average values for one week, the week were numbered since the restart of water washing for each injection (Phase 1, Phase 2, Phase 3).

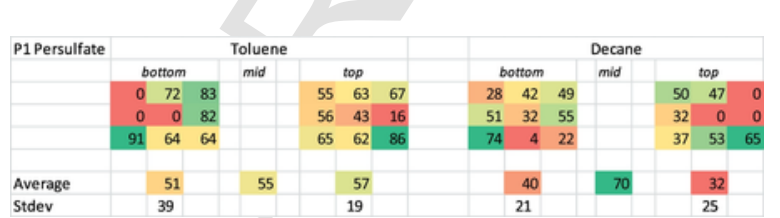

Fig. 4. Toluene and $n$-decane removal (\%) from polluted lenses in the Tank 1 (oxidation) after conditioning period and persulfate treatment. For the top and bottom lenses, the values show the removal for the 9 samples taken for each lens, while only one sample was taken in the mid lens (the colors are proportional to removal values).

There was no higher removal on the sides of the lenses, which could have been expected in presence of dissolution in a homogeneous medium. On average, n-decane removal (47\%) was similar to toluene one, with higher removal rates $(70 \%)$ in the mid lens and lower ones $(32-40 \%)$ in the less permeable lenses. This high n-decane removal tends to show that the dissolution process was not limiting and also that oxidation of n-decane might have been important. It was also shown in a column study (Jousse et al., 2016) that the removal rates of n-decane and toluene were similar during oxidation with medium persulfate concentrations $\left(10-100 \mathrm{~g} \mathrm{~L}^{-1}\right)$.

\subsubsection{Surfactant}

A Tween80 $®$ solution was injected at flow rates varying between 60 and $180 \mathrm{~L} \mathrm{day}^{-1}$ compared to the $45 \mathrm{~L} \mathrm{day}^{-1}$ of tap water during conditioning period. The concentrations sampled at the outlet of the tank are given in Fig. 5. As already outlined the outflowing toluene concentrations were quite variable during the conditioning period. During the surfactant flushing outlet concentrations showed less variation than during the water flushing, including a slow decrease (3.5 to $2.5 \mathrm{~g} / \mathrm{PV}$ ). The removed amounts did not seem to depend on surfactant flow rate. Indeed, the same amount of toluene was flowing out of the

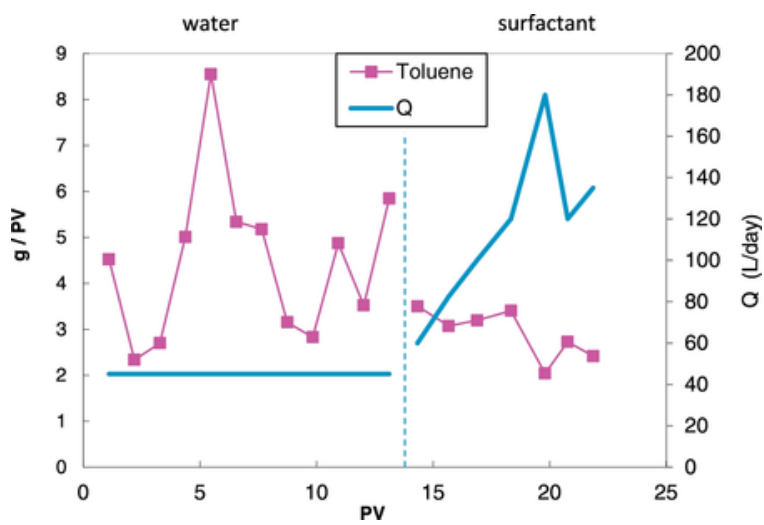

Fig. 5. Evolution of the outflowing toluene amount from Tank 2 (surfactant) as a function of the number of pore volume during water and surfactant flushing. The discharge through the pilot $(\mathrm{Q})$ is also presented. 
tank with flow rates varying from 60 to $180 \mathrm{~L} \mathrm{day}^{-1}$ (from 14.4 to $23 \mathrm{PV}$ ). This suggests a limitation of the removal by a slow dissolution of the NAPL blobs.

The remaining NAPL masses, measured after tank dismounting, differ significantly from persulfate treatment (Fig. 6). In the permeable lens the toluene removal was higher $(78 \%)$ than for oxidation (55\%), while in the less permeable lenses they were lower, 33\% compared to $54 \%$ for oxidation. For n-decane the difference was even higher: the removal rates were close to zero everywhere in the top and bottom lenses. Therefore, it seems that the flow differences and the dissolution rates played a major role for that treatment technique.

It was possible to calculate mass balance in this treatment as the pollutant was not destroyed and all the toluene was extracted with the fluid. The mass balance analysis showed only a 1\% difference between the amounts recovered at the tank outlet and the ones calculated from the remaining mass in the tank. This small difference validates all the analytical procedure achieved in liquid and solid phase.

In the bottom lens, the n-decane analyses show no removal while toluene was removed. However, in the top lens n-decane removal can be as high as $45 \%$, with $61 \%$ toluene removal. Even considering potential analytical variations this difference suggests that the solubility is not the only mechanism that may justify the remaining $\mathrm{n}$-decane mass.

\subsubsection{Sparging with air and ozone}

3.2.3.1. Air injection During sparging with air followed by ozone (Tank 3 ), the toluene concentrations in gas phase sampled on top of the tank with a Tedlar bag are given in Fig. 7. The concentrations were highly variable, varying from 0 to $50 \mathrm{mg} \mathrm{L}^{-1}$, particularly during the first 10 days of treatment. Due to these variations, it was not possible to correctly assess a mass balance of the toluene recovered in gas phase. However, three periods can be identified: (i) during the first 15 days the concentrations were highly variable and reached very high values (up to $100 \mathrm{mg} \mathrm{L}^{-1}$ in the gas phase) (ii) then during the next 15 days the concentrations were quite low, varying between 0.5 and $3 \mathrm{mg} \mathrm{L}^{-1}$, and finally after day 25 the concentrations were under detection limit mainly due to the ozone addition.

The final content in sand, given in Fig. 8, showed a behavior intermediate between oxidation and surfactant: the toluene removal was higher in the middle lens (61\%) but was also significant in the low hydraulic conductivity lenses
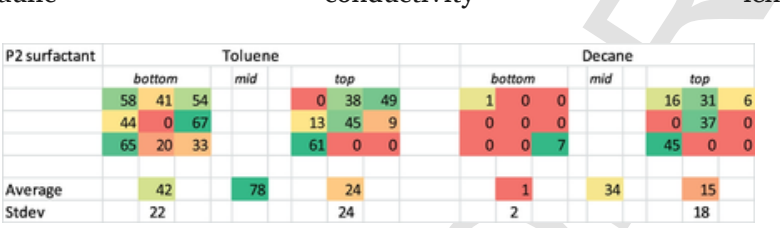

Fig. 6. Toluene and n-decane removal (\%) in the Tank 2 (surfactant) after conditioning period and surfactant treatment (same representation as Fig. 4).

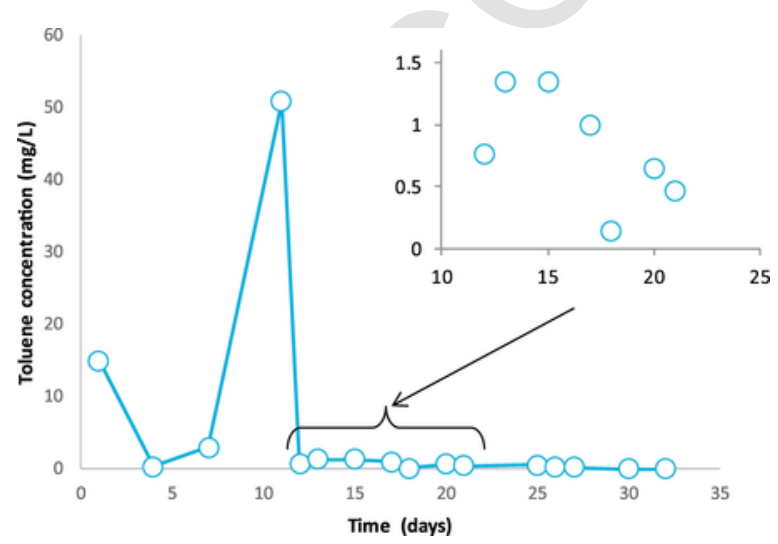

Fig. 7. Temporal evolution of toluene concentrations in the gas phase sampled in Tedlar bags on top of Tank 3 (sparging).

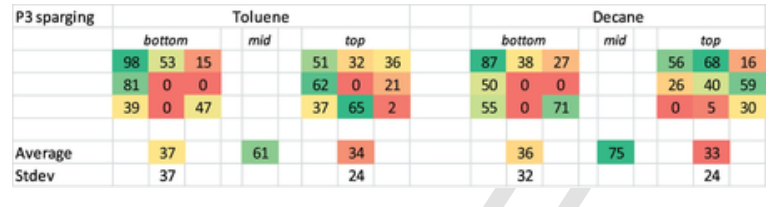

Fig. 8. Toluene and n-decane removal (\%) in the Tank 3 (sparging) after conditioning period and sparging with air and ozone.

(35\%). Average n-decane removals were quite close to toluene removals. Because the vapor pressure of $n$-decane is more than 20 times lower than that of toluene, a consequent difference in removal rates should have been observed. For the bottom lens, very high and very low removal rates were observed at the same location for toluene and n-decane. This correlation was not observed in the top lens.

The important variations in gas phase concentrations given in Fig. 7 showed that the process was not at equilibrium during sparging. In the literature, several experiments conducted in 2D tanks showed that, at high air flow rates, sparging led to precisely located gas channels (Rogers and Ong, 2000). It is possible that the same process happened in tank 3. Fast flow of air in channels could remove the most volatile pollutant at the beginning and remove the less volatile one on a longer time scale. This temporal variation is consistent with the spatial pattern of the removal: at some places the removal was undetected, which means that there were no air channels at these locations, while at others, due to the presence of one or several air channels, the removal was high. 3.2.3.2. Ozone injection As it was not possible to determine the amount of contaminant remaining after the air sparging phase, it is difficult to assess the specific role of ozone during the treatment. However, the toluene gas concentration was quite low after air sparging which reflects low concentrations in the air channels. It is therefore supposed that the toluene oxidation by ozone might be low, removing less than $0.5 \mathrm{mg} \mathrm{L}^{-1}$ toluene. However, ozone could have had an effect on the concentrations of $\mathrm{n}$-decane remaining after the sparging.

\subsubsection{Thermal treatment}

Thermal treatment was applied by heating the bottom of tank 4 without water circulation. This led to a higher temperature at the bottom of the tank $\left(85^{\circ} \mathrm{C}\right)$ than at the position of the upper lens $\left(75^{\circ} \mathrm{C}\right)$. The concentrations of toluene, sampled in Tedlar bags at the top of the tank, were increasing during temperature raising, reaching values close to vapor pressure (Fig. S5) and then decreasing rapidly after 20 days of heating.

Fig. 9 shows that the removal was almost complete for the bottom and mid lens while it was around $63 \%$ for the top lens. These data represent the highest removal rates of all tanks. Moreover, the removal yield of the top lens would have been the same as the bottom one in real situation where, unlike in the pilot, the heated region is much larger and thus the thermal gradient occurs mainly close to the soil surface.

Even with thermal treatment, if the removal is not complete, a significant standard deviation remains. This removal heterogeneity could be attributed to the variable permeability in the lens, as it was shown elsewhere that a lower permeability yield a lower removal rate (Jousse et al., 2016). In this case, n-decane showed lower removal rates (39\%) than toluene $(63 \%)$. However, the difference was much smaller than what could be predicted from the vapor pressure of the two substances, which differ by two orders of magnitude.

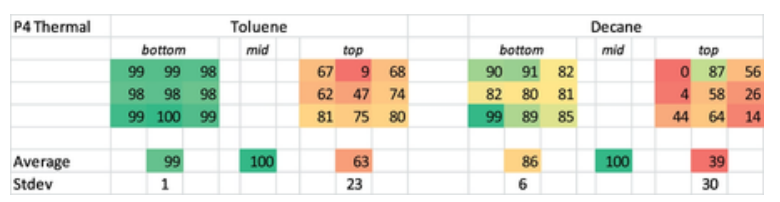

Fig. 9. Toluene and n-decane removal (\%) in the Tank 4 (thermal) after conditioning period and thermal treatment. 


\subsection{Discussion}

\subsubsection{Global comparison}

From a global point of view, it is clear that low temperature thermal treatment is the most efficient technique, reaching efficiency higher than $99 \%$ if the target temperature is reached, and approximately $80 \%$ for the whole tank under the tested conditions (Table 2). The other remediation techniques gave, considering the high standard deviations, similar removal rates of approximately $50 \%$ of the total contamination. It must be reminded that these removal rates include water washing at high velocities (conditioning period) before the treatments. From our experience, we ruled out biodegradation because tap water treated by chlorine was used to wash the tanks and the residence time was at most 4 days. Some differences could be identified: (i) persulfate oxidation leads to the highest removal rates in the low permeability lenses, while (ii) surfactant and sparging reached much lower efficiencies for these lenses. These differences could potentially be due to the effect of solution density that allowed the persulfate solution arriving on top of the lenses to slowly penetrate these ones during the 7 days without water flow (Cavanagh et al., 2014).

\subsubsection{Mass-flux relations}

The mass-flux relations were analyzed in two steps: the conditioning period and the treatment phase for persulfate and surfactant tanks. Indeed, for sparging and thermal techniques the outgoing contaminant flux is only flowing out during the conditioning period and cannot be compared to the other experiments. The mass flux relations could only be analyzed for toluene as n-decane was not recovered in the pumping wells. For surfactant the removed mass is calculated from pollutant mass in the outflow. For persulfate the removed mass is obtained precisely for the end of phase 3 and estimated from persulfate amounts added for the previous phases.

The concentration of toluene flowing out of the pilots is presented in Fig. 10 as a function of the mass removed. The representation is similar to mass-flux relations (Fure et al., 2006) as the flux is directly proportional to concentration in these experiments. Considering dissolution under Raoult's law equilibrium and neglecting dispersion, an estimated theoretical outflowing concentration of toluene of approximately $19.5 \mathrm{mg} \mathrm{L}^{-1}$ can be estimated. Fig. 10 shows that the starting value was around $20 \mathrm{mg} \mathrm{L}^{-1}$ which is consistent with the theoretical value, indicating equilibrium dissolution at the beginning of the experiments.

Among the tanks, except for Tank 1 (oxidation), the three tanks showed a significant flux decrease at the end of the curve. For Tank 1 (oxidation) the decrease was not obvious during this period. It must be noticed that the decrease occurred at quite different mass removed: from 32 to more than 40\%, although

Table 2

Total amounts (in $\mathrm{g}$ ) and percentage of pollutants removed from the tanks during the conditioning and treatment periods, calculated from pollutant mass outflowing from the tanks for conditioning and from data in Figs. 4, 6, 8 and 9 for treatment. (the error was calculated through the total analytical standard deviation divided by the number of samples, * shows data that were obtained by difference and thus without measurement error).

\begin{tabular}{|c|c|c|c|c|}
\hline Tank & $\begin{array}{l}1 \\
\text { Persulfate }\end{array}$ & $\begin{array}{l}2 \\
\text { Surfactant }\end{array}$ & $\begin{array}{l}3 \\
\text { Sparging }\end{array}$ & $\begin{array}{l}4 \\
\text { Thermal }\end{array}$ \\
\hline $\begin{array}{l}\text { Toluene } \\
\text { removed by } \\
\text { conditioning } \\
\text { (g) }\end{array}$ & $\begin{array}{l}64.9 \pm 0.6 \\
(38 \%)\end{array}$ & $\begin{array}{l}57.8 \pm 0.6 \\
(33 \%)\end{array}$ & $\begin{array}{l}54.4 \pm 0.5 \\
(31 \%)\end{array}$ & $\begin{array}{l}57.1 \pm 0.1 \\
(33 \%)\end{array}$ \\
\hline $\begin{array}{l}\text { Toluene } \\
\text { removed by } \\
\text { treatment } \\
(\mathrm{g})^{*}\end{array}$ & $\begin{array}{l}29 \\
(17 \%)\end{array}$ & $\begin{array}{l}25 \\
(14 \%)\end{array}$ & $\begin{array}{l}22 \\
(13 \%)\end{array}$ & $\begin{array}{l}94 \\
(54 \%)\end{array}$ \\
\hline $\begin{array}{l}\text { Toluene } \\
\text { remaining } \\
\text { (g) }\end{array}$ & $\begin{array}{l}79 \pm 4.8 \\
(46 \%)\end{array}$ & $\begin{array}{l}90 \pm 5.4 \\
(52 \%)\end{array}$ & $\begin{array}{l}97 \pm 5.9 \\
(56 \%)\end{array}$ & $\begin{array}{l}22 \pm 1.3 \\
(13 \%)\end{array}$ \\
\hline $\begin{array}{l}\text { Total } \\
\text { decane } \\
\text { removed } \\
(\mathrm{g})^{*}\end{array}$ & $\begin{array}{l}67 \\
(47 \%)\end{array}$ & $\begin{array}{l}24 \\
(17 \%)\end{array}$ & $\begin{array}{l}68 \\
(48 \%)\end{array}$ & $\begin{array}{l}107 \\
(75 \%)\end{array}$ \\
\hline $\begin{array}{l}\text { Decane } \\
\text { remaining }\end{array}$ & $\begin{array}{l}75 \pm 4.5 \\
(53 \%)\end{array}$ & $\begin{array}{l}119 \pm 7.2 \\
(83 \%)\end{array}$ & $\begin{array}{l}74 \pm 4.5 \\
(52 \%)\end{array}$ & $\begin{array}{l}35 \pm 2.1 \\
(25 \%)\end{array}$ \\
\hline
\end{tabular}

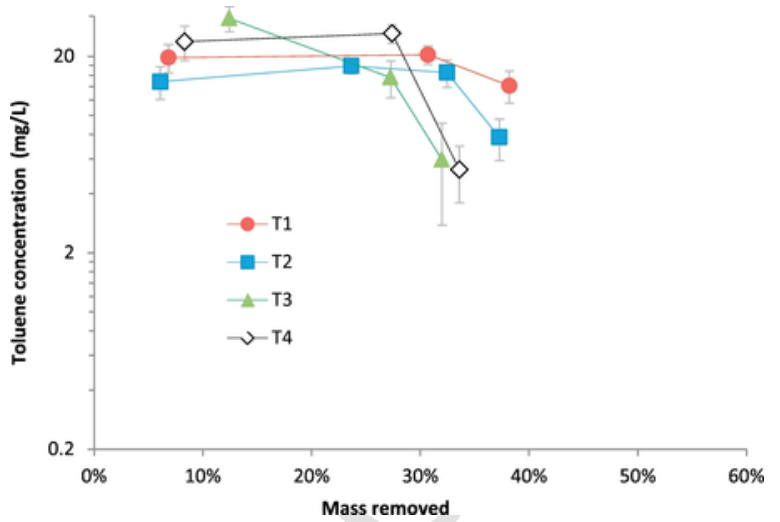

Fig. 10. Average toluene concentration evolution at the outlet of all tanks during the conditioning period, given as function of the mass removed.

the tanks were built exactly in the same way. It seems that small local differences in initial concentrations or hydraulic conductivity can lead to quite variable fluxes for the same mass removed. Fig. 10 shows that when the decrease started it was quite rapid (the vertical axis in the figure is log transformed). This behavior might be explained by some experiments conducted by other authors (e.g. Nambi and Powers, 2000). During conditioning, a slight initial heterogeneity is enhanced by water flow because a zone of lower oil content, having a relative high permeability, is more rapidly washed (Jawitz et al., 2005; Powers et al., 1994). In contrast, a zone having high oil content can remain almost unaffected by the dissolution process. Before the complete oil depletion in the faster channels, the outflow concentration remains close to solubility. However, when the faster channels become depleted, a significant proportion of the flow may contain very low concentrations of toluene (e.g. 1\% solubility) leading to a rapid decrease in concentrations. This explanation is quite consistent with the high heterogeneity observed in the lenses after treatment, reaching 0 to $90 \%$ oil content in less than $9 \mathrm{~cm}$.

The same approach has been conducted on the results of the treatment phase, for persulfate and surfactant addition (Fig. 11). First of all, the persulfate curve has a shape quite similar to the other tanks, except that the concentration decrease began around $40 \%$ of mass removed. During the persulfate treatment, the curve decreased rapidly to a concentration of $0.9 \mathrm{mg} \mathrm{L}^{-1}$ for $53 \%$ mass removed.

The results for surfactant are different. They required a calculation as the washing was conducted with surfactant solution and not only with water. The presented concentrations were obtained by dividing the measured concentration by the Tween 80 to water solubility ratio of toluene (2.5). The data show that the corrected concentrations for the first days of surfactant addition were very similar to the one of the last days of the conditioning period, 5.5 and $6.5 \mathrm{mg} \mathrm{L}^{-1}$ respectively. The surfactant washing is less efficient than for per-

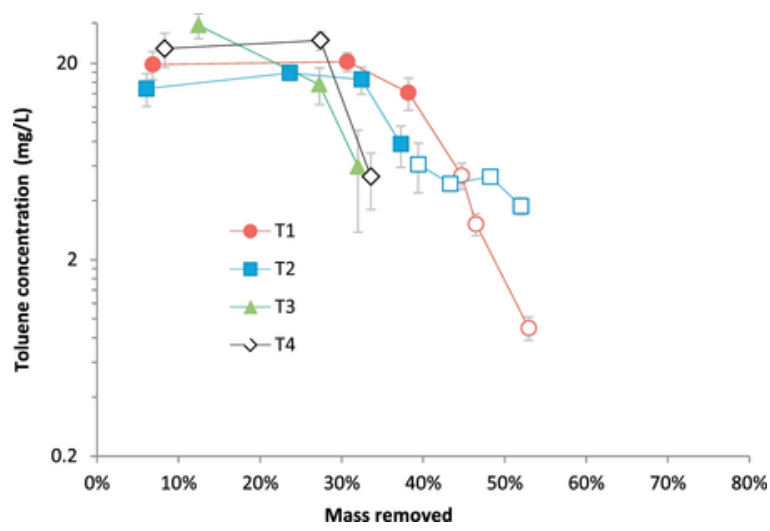

Fig. 11. Evolution of the toluene concentrations at the tanks outlet during the conditioning and treatment periods as a function of the mass removed in the tanks. 
sulfate because the flux is less reduced for the same mass removal. This result can be linked to the treatment efficiency in the different lenses: persulfate treatment showed a removal close to $55 \%$ in all lenses, while surfactant showed a higher removal in the mid-lens (78\%) but a low efficiency in the low permeability lenses (33\% in average). If a removal lower than $40 \%$ of the mass in the lenses leads to a concentration equal to solubility, as observed for all tanks, the surfactant low permeability lenses may still deliver concentrations equal to solubility.

As observed by several authors (Adamson et al., 2011; Liu and Ball, 2002), a significant release of contaminant can come from low hydraulic conductivity layers and the most efficient techniques are the ones that treat these layers. In the present situation dense persulfate solutions were chosen specifically to penetrate the low permeability lenses. This approach seems to be successful. On the other hand, although surfactant enhances the solubility, the flowing solution is still largely limited by low hydraulic conductivity zones. The average removal for surfactant treatment compared to other studies (Ramsburg et al., 2005), may also be linked to the low enhancement of solubility (2.5) for toluene compared to enhancement higher than 50 obtained for chlorinated solvents (Pennell et al., 1994).

\subsubsection{Long term predictions}

The experiments could not be continued until reaching a complete depletion of mass or flux. Thus, an extrapolation is required to get the final results. Two approaches can be considered depending on the site and the remedial objective: removing the maximum of the mass, or of the flux. If the mass in the source is considered, the best technique is obviously the thermal treatment, because this is the only one that is able to approach $100 \%$ removal. For the flux approach, a target decrease of $99 \%$ of the flux may be considered.

To predict the exported flux for persulfate and surfactant treatment, an empirical fitting of the concentration-mass curves was chosen. None of the classical dissolution models (Zhang et al., 2008) were satisfactory for persulfate, may be because we consider a reactive treatment process and not pure dissolution. The best fitting curve for both treatments was of type:

$\log _{10}\left(\frac{C}{C_{0}}\right)=1.3 \operatorname{Erfc}((\%, M,-, a), \cdot, b)-2$

where $C$ and $C_{0}$ are concentrations in any units, $\mathrm{M}$ is the $\%$ of mass removed, and $\mathrm{a}$ and $\mathrm{b}$ are arbitrary coefficients. Although looking similar to previous approaches (Falta et al., 2005; Jawitz et al., 2005) it considers the logarithm of the concentration which leads to a faster decrease than a linear relation. For surfactant several models could be adapted but for consistency the same formula was used.

For persulfate the curve fits quite well and thus the uncertainty on the extrapolation is small. It can be seen on Fig. 12 that the objective of $99 \%$ removal of the flux, or concentration, is reached when approximately $60 \%$ of the mass is removed.

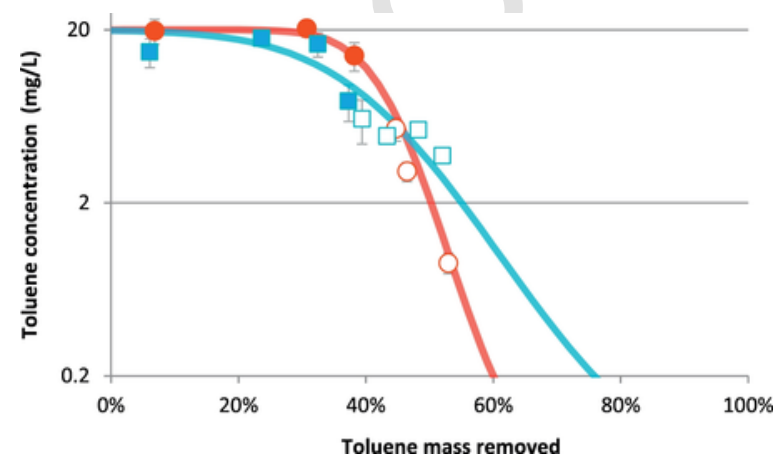

Fig. 12. Curve fitting of the concentration-mass curves. Red: Persulfate (a: 0.53, b: 7.5), Blue: Surfactant (a: 0.61 , b: 3.5 ). The error bars show the standard deviation of the concentrations measured during 5 days. (For interpretation of the references to colour in this figure legend, the reader is referred to the web version of this article.)
In order to make predictions, the number of necessary pore volumes to reach a given mass removal for each treatment was used. These pore volumes are true pore volumes for surfactant solution but for persulfate they include the addition of a concentrated solution of persulfate followed by water washing.

Fig. 13 shows that surfactant data show a clear linear trend in the log-linear graph relating used pore volumes with mass removal. Persulfate data are more erratic but follow the same trend. In order to make predictions, the surfactant exponential curve fitted to the points was extended and shown as a black straight line. Table 3 presents the number of pore volumes and mass required for a treatment leading to a $99 \%$ flux reduction. The surfactant treatment requires approximately 5 times more PV to reach the same target because it decreases much slowly than persulfate. If only the mass of the added substance is considered, the total mass of surfactant $(0.32 \mathrm{~kg})$ remains much smaller than the persulfate one $(4 \mathrm{~kg})$. However, the mass of product represents only a small part of the costs. Water treatment must be added for surfactant, but not for persulfate, as well as human costs which are proportional to treatment time.

Fig. 13 also shows a "model" curve which was calculated from the surfactant treatment data to estimate the water PV required in a simple pump and treat system. In order to reach a full treatment, the use of pump and treat would have required 370 pore volumes of water. This graph explains the difficulty of using pump and treat in real systems: its efficiency decreases rapidly as the concentration of the pollutant in the extraction water decreases. However, it also shows that in the first stages of a treatment, water washing ( $=$ pump and treat) is as efficient as other techniques. Indeed, during this period the pollutant is at equilibrium concentration and thus the outlet flux is quite high.

Concerning sparging the same approach cannot be used as no water flux was imposed between treatment phases. However, as shown previously there was a high peak of toluene concentration in the gas phase (50 $\mathrm{mg} \mathrm{L}^{-1}$ air) and then, before the ozone injection, the toluene gas concentrations were pretty low but quite stable and measurable. The average concentration is $0.9 \mathrm{mg} \mathrm{L}^{-1}$ air.

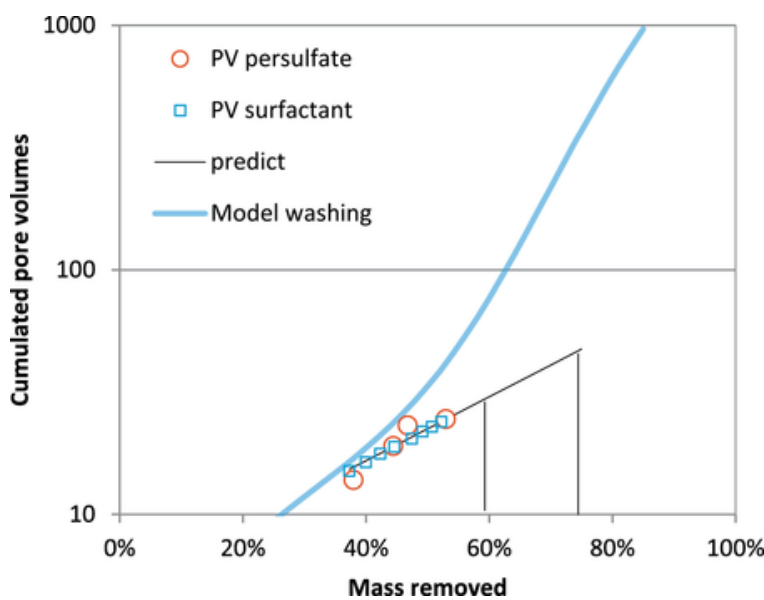

Fig. 13. Evolution of the cumulated pore volumes (PV) of added treatment or simply water (model) for persulfate and surfactant treatments as a function of the mass removed in the tanks (error bars on PV are smaller than point size). The "predict" line is an exponential trend fitted on the PV surfactant curve. Vertical lines show the mass removal required to reach $99 \%$ flux removal.

Table 3

Estimated pore volumes (PV) and associated mass to reach the $99 \%$ percent flux reduction for each treatment technique (error is estimated from model fitting in Fig. 12 using measurement error bars, and from Fig. 13 using the correlation error in the concerned range)

\begin{tabular}{lll}
\hline & Persulfate & Surfactant \\
\hline $\begin{array}{l}\text { \% mass removal required for 99\% flux } \\
\text { decrease }\end{array}$ & $59.5 \pm 1$ & $75 \pm 2.4$ \\
Nb of required PV predicted from fit & $16.2 \pm 1.1$ & $32.5 \pm 4.1$ \\
Nb of PV added during treatment & $10.7 \pm 0.1$ & $8.9 \pm 0.09$ \\
Corresponding mass of reagent $(\mathrm{kg})$ & $4.0 \pm 0.01$ & $0.32 \pm 0.001$ \\
Required PV to reach target & $5.5 \pm 1.1$ & $23.6 \pm 4.1$ \\
Additional mass required $(\mathrm{kg})$ & $2.06 \pm 0.4$ & $0.85 \pm 0.16$ \\
Total mass of reagent $(\mathrm{kg})$ & 6.06 & 1.17
\end{tabular}


This low concentration also suggests that sparging is limited by diffusion when contaminants around the air channels slowly diffuse towards them (Chao et al., 2008). It can thus be supposed that this low toluene concentration can remain stable until most of the mass will be depleted. Sparging reached similar distribution of residual content in the lenses of variable permeability and it can thus be supposed that a 75\% mass removal is the target, as for surfactant. In order to reach $75 \%$ removal, or remove $54 \mathrm{~g}$ more, this would require approximately 100 more days of sparging treatment.

\subsubsection{Solubility effects}

Figs. 4, 6, 8 and 9 showed the residual mass of n-decane and toluene. Unfortunately, due to its low solubility n-decane could not be recovered from extracted solutions or gas phase during the experiments. Due to the n-decane properties relative to toluene (Table 4), one could think that the n-decane removal should have been much lower in all pilots, while it is only the case for surfactant treatment. Potential explanations are as follows. For sparging, the differences in vapor pressure may not be seen because toluene was rapidly removed from the channels at the beginning and then n-decane was slowly removed at the same place but at the end the overall rate may be driven by the air channels density. For thermal treatment, toluene co-boils with water and n-decane seems to be present at high concentrations in the gas bubbles, leading to n-decane elimination. For oxidation, it seems that the removed n-decane/toluene ratio is varying according to the concentration of persulfate (Jousse et al., 2016). It then appears that several processes may contradict a simple use of solubility differences and Raoult's law to extrapolate the behavior of one compound to another one.

\section{Conclusion}

The comparison of four 3D experiments in mildly heterogeneous media containing NAPL lenses based on different remediation techniques revealed important findings. At first, the thermal treatment is the only one that can easily approach $100 \%$ mass removal, and thus is not dependent on heterogeneity. Due to the effect of co-boiling, it is not necessary to reach $100{ }^{\circ} \mathrm{C}$ to obtain this efficiency; the temperature has to be calculated for each NAPL mixture but is often around $80{ }^{\circ} \mathrm{C}$.

For the three other techniques, an approach based on $100 \%$ mass removal would require enormous injection amounts, but an objective of 99\% flux removal can often be accepted. For this purpose a conceptual modeling approach was developed by relating the outflowing concentration to the mass removed. A logarithmic representation was used to emphasize the low concentrations. This approach clearly differentiates oxidation and surfactant efficiency. Indeed, the treatment technique that was able to better treat the low hydraulic conductivity lenses, namely oxidation, reached more rapidly the flux-based cleaning goal. It seems that this simplified approach can be of great help to assess the most efficient treatment technique in the field.

The oxidation approach was more efficient on low hydraulic conductivity lenses because dense solutions were used and special attention was given to fo- cus the dense solution on the top of the low hydraulic conductivity lenses. On the other hand, it seems that, except enhancing the pollutant solubility, surfactant injection behaves quite similarly to water flushing. It therefore seems that it is not an adapted technique to target low hydraulic conductivity lenses. It was initially supposed that the sparged air would, by penetrating vertically in the lenses; more easily deplete them from contaminant. It does not seem to be the case, leading to long treatment times in sparging.

This study confirms that heterogeneity is the main limitation of the treatments efficiency, as already shown by several studies (Illangasekare et al., 2006; Jawitz et al., 2003; Kaye et al., 2008). Indeed, the presented techniques were tested in columns and showed removal efficiencies higher than $90 \%$. Owing to relative permeability effects, the presence of NAPL increases the heterogeneity effects. As the techniques based on fluid flow (surfactant, sparging) are too sensitive to the heterogeneity, different strategies can be suggested:

- The combined use of oxidation with a dense fluid on top of the contamination, as gravity surpassing horizontal flow in zones of low $\mathrm{K}$, will allow to treat them.

- The techniques based on heat dissipation can be used as they are largely insensitive to heterogeneity in permeability.

- Local modification of the flow directions could limit heterogeneity effects

- A focused local treatment, at the $\mathrm{dm}$ scale, as done through direct push techniques.

Besides the treatments used in this paper, recent literature emphasizes the potential of mixed techniques. However, our study shows that a proof of concept needs to be done at the $\mathrm{m}^{3}$ scale, and that these techniques must avoid classical flow patterns to reach significant efficiencies. In this area, the addition of polymer or foam could be a solution as it can provide a way to target the zones with low permeability.

This study also outlines that the long term removal ratio of different pollutant present in a NAPL phase cannot be calculated from Raoult's law, although the law shall apply at the local scale.

\section{Acknowledgments}

The authors would like to thank the partner companies of the INNOVASOL Foundation which permitted the set-up of this research project. They also would like to thank the anonymous reviewers who helped to improve the quality of this paper.

\section{Appendix A. Supplementary data}

5 figures showing temporal evolutions of concentrations at the outlet of the pilot tanks. Supplementary data associated with this article can be found in the online version, at 10.1016/j.jconhyd.2017.04.006.

Table 4

Amounts, equilibrium concentrations and vapor pressures (data from Schwarzenbach et al., 2002 using Raoult's law) of toluene and n-decane in each lens.

\begin{tabular}{|c|c|c|c|c|c|c|c|}
\hline & Volume & Mass & Amount & Solubility & Equilibrium concentration & Vapor pressure & Equilibrium pressure \\
\hline & $\mathrm{mL}$ & $g$ & mole & $\mathrm{mmol} \mathrm{L}-1$ & $\mathrm{mmol} \mathrm{L}^{-1}$ & $\mathrm{~Pa}$ & $\mathrm{~Pa}$ \\
\hline Toluene & 66 & 57.4 & 0.648 & 6.025 & 3.90 & 3715 & 2406 \\
\hline n-Decane & 66 & 48.2 & 0.352 & $3.84 \cdot 10^{-4}$ & $1.34 \cdot 10^{-4}$ & 173 & 44.4 \\
\hline
\end{tabular}




\section{References}

Adamson, D.T., McGuire, T.M., Newell, C.J., Stroo, H., 2011. Sustained treatment: implications for treatment timescales associated with source-depletion technologies. Remediat. J. 21, 27-50. http://dx.doi.org/10.1002/rem.20280.

Barnier, C., Palmier, C., Atteia, O., 2013. Field evidence of dissolution and degradation rates enhancement during ISCR and ENA treatments of chlorinated solvents. Environ. Technol. 123-137 (Winter).

Braida, W.J., Ong, S.K., 2001. Air sparging effectiveness: laboratory characterization of air-channel mass transfer zone for VOC volatilization. J. Hazard. Mater. 87, 241-258. http://dx.doi.org/10.1016/S0304-3894(01)00287-4.

Brooks, M.C., Wood, A.L., Annable, M.D., Hatfield, K., Cho, J., Holbert, C., Rao, P.S.C., Enfield, C.G., Lynch, K., Smith, R.E., 2008. Changes in contaminant mass discharge from DNAPL source mass depletion: evaluation at two field sites. J. Contam. Hydrol. 102, 140-153. http://dx.doi.org/10.1016/j.jconhyd.2008.05.008.

Burghardt, J.M., Kueper, B.H., 2008. Laboratory study evaluating heating of tetrachloroethylene impacted soil. Ground Water Monit. Remediat. 28, 95-106. http://dx. doi.org/10.1111/j.1745-6592.2008.00214.x.

Cavanagh, B.A., Johnson, P.C., Daniels, E.J., 2014. Reduction of diffusive contaminant emissions from a dissolved source in a lower permeability layer by sodium persulfate treatment. Environ. Sci. Technol. 48, 14582-14589. http://dx.doi.org/10.1021/ es5040443.

Chao, K., Kee, S., Huang, M., 2008. Mass transfer of VOCs in laboratory-scale air sparging tank. J. Hazard. Mater. 152, 1098-1107. http://dx.doi.org/10.1016/j.jhazmat.2007. 07.087.

Chen, M.-R., Hinkley, R.E., Killough, J.E., 1996. Computed tomography imaging of air sparging in porous media. Water Resour. Res. 32, 3013-3024. http://dx.doi.org/10. 1029/96WR01136.

Cohen, G., Jousse, F., Luze, N., Hohener, P., Atteia, O., 2016. LNAPL source zone delineation using soil gases in a heterogeneous silty-sand aquifer. J. Contam. Hydrol. 192, http://dx.doi.org/10.1016/j.jconhyd.2016.06.001.

Cohen, G.J., Jousse, F., Luze, N., Höhener, P., Atteia, O., 2016. LNAPL source zone delineation using soil gases in a heterogeneous silty-sand aquifer. J. Contam. Hydrol. 192, 20-34. http://dx.doi.org/10.1016/j.jconhyd.2016.06.001.

Conrad, S.H., Glass, R.J., Peplinski, W.J., 2002. Bench scale visualization of DNAPL remediation processes in analog heterogeneous aquifers: surfactant floods and in situ oxidation using permanganate. J. Contam. Hydrol. 13, 49.

Difilippo, E.L., Brusseau, M.L., 2008. Relationship between mass-flux reduction and source-zone mass removal: analysis of fi eld data. J. Contam. Hydrol. 98, 22-35. http: //dx.doi.org/10.1016/j.jconhyd.2008.02.004.

Falta, R.W., Rao, P.S.C., Basu, N.B., 2005. Assessing the impacts of partial mass depletion in DNAPL source zones - I. Analytical modeling of source strength functions and plume response. J. Contam. Hydrol. 78, 259-280.

Fure, A.D., Jawitz, J.W., Annable, M.D., 2006. DNAPL source depletion: linking architecture and flux response. J. Contam. Hydrol. 85, 118-140.

Heron, G., Van Zutphen, M., Christensen, T.H., Enfield, C.G., 1998. Soil heating for en hanced remediation of chlorinated solvents: a laboratory study on resistive heating and vapor extraction in a silty, low-permeable soil contaminated with trichloroethylene. Environ. Sci. Technol. 32, 1474-1481. http://dx.doi.org/10.1021/es970563j.

Hood, E.D., 2000. Permanganate Flushing of DNAPL Source Zones: Experimental and Numerical Investigation. (Waterloo, Canada).

Illangasekare, T.H., Marr, J.M., Siegrist, R.L., Soga, K., Glover, K.C., Moreno-Barbero, E. Heiderscheidt, J.L., Saenton, S., Matthew, M., Kaplan, A.R., Kim, Y., Dai, D., Gago, J.L., Page, J.W.E., 2006. Mass Transfer from Entrapped DNAPL Sources Undergoing Remediation: Characterization Methods and Prediction Tools. 437.

Jawitz, J.W., Dai, D., Rao, P.S.C., Annable, M.D., Rhue, R.D., 2003. Rate-limited solubilization of multicomponent nonaqueous-phase liquids by flushing with cosolvents and surfactants: modeling data from laboratory and field experiments. Environ. Sci. Technol. 37, 1983-1991. http://dx.doi.org/10.1021/es0256921.

Jawitz, J.W., Fure, A.D., Demmy, G.G., Berglund, S., Rao, P.S.C., 2005. Groundwater contaminant flux reduction resulting from non aqueous pahse liquid mass reduction. Water Resour. Res. 41 (10)http://dx.doi.org/10.1029/2004WR003825.
Jousse, F., Atteia, O., Hohener, P., Cohen, G., 2016. Removal of NAPL from columns by oxidation, sparging, surfactant and thermal treatment. J. Hazard. Mater. (Submitted)

Kawala, Z., Atamańczuk, T., 1998. Microwave-enhanced thermal decontamination of soil Environ. Sci. Technol. 32, 2602-2607. http://dx.doi.org/10.1021/es980025m.

Kaye, A.J., Cho, J., Basu, N.B., Chen, X., Annable, M.D., Jawitz, J.W., 2008. Laboratory investigation of flux reduction from dense non-aqueous phase liquid (DNAPL) partia source zone remediation by enhanced dissolution. J. Contam. Hydrol. ( $\{\mathrm{PhD}\}$ Dissertation, Colorado School of Mines) 10.1016/j.jconhyd.2008.01.006.

Liu, C., Ball, W.P., 2002. Back diffusion of chlorinated solvent contaminants from a natural aquitard to a remediated aquifer under well-controlled field conditions: predictions and measurements. Ground Water 40, 175-184.

Londergan, J.T., Meinardus, H.W., Mariner, P.E., Jackson, R.E., Brown, C.L., Dwarakanath, V., Pope, G.A., Ginn, J.S., Taffinder, S., 2001. DNAPL removal from a heterogeneous alluvial aquifer by surfactant-enhanced aquifer remediation. Ground Water Monit. Remediat. 21, 57-67. http://dx.doi.org/10.1111/j.1745-6592.2001.tb00642.x.

Mackinnon, L.K., Thomson, N.R., 2002. Laboratory-scale in situ chemical oxidation of a perchloroethylene pool using permanganate. 56, 49-74.

McCray, J.E., Tick, G.R., Jawitz, J.W., Gierke, J.S., Brusseau, M.L., Falta, R.W., Knox, R.C., Sabatini, D.A., Annable, M.D., Harwell, J.H., Wood, A.L., 2011. Remediation of NAPI source zones: lessons learned from field studies at hill and dover AFB. Ground Water 49 (5), 727-744. http://dx.doi.org/10.1111/j.1745-6584.2010.00783.x.

Nambi, I.M., Powers, S.E., 2000. NAPL dissolution in heterogeneous systems: an experimental investigation in a simple heterogeneous system. J. Contam. Hydrol. 44 (2), 161-184.

Oostrom, M., Hofstee, C., Walker, R.C., Dane, J.H., 1999. Movement and remediation of trichloroethylene in a saturated, heterogeneous porous medium 2. Pump-and-treat and surfactant flushing. J. Contam. Hydrol. 37, 179-197.

Page, J.W.E., Soga, K., Illangasekare, T., 2007. The significance of heterogeneity on mass flux from DNAPL source zones: an experimental investigation. J. Contam. Hydrol. 94, 215-234.

Pennell, K.D., Jin, M., Abriola, L.M., Pope, G.A., 1994. Surfactant enhanced remediation of soil columns contaminated by residual tetrachloroethylene. J. Contam. Hydrol. 16, 35-53. http://dx.doi.org/10.1016/0169-7722(94)90071-X.

Powers, S.E., Abriola, L.M., Dunkin, J.S., Weber, W.J., 1994. Phenomenological models for transient NAPL-water mass-transfer processes. J. Contam. Hydrol. 16, 1-33. http: //dx.doi.org/10.1016/0169-7722(94)90070-1.

Ramsburg, C.A., Pennell, K.D., Abriola, L.M., Daniels, G., Drummond, C.D., Gamache, M., Hsu, H., Petrovskis, E.A., Rathfelder, K.M., Ryder, J.L., Yavaraski, T.P., 2005. Pilot-scale demonstration of surfactant-enhanced $\{\mathrm{PCE}\}$ solubilization at the Bachman road site. 2. System operation and evaluation. Environ. Sci. Technol. 39, 1791-1801. http://dx.doi.org/10.1021/es049563r.

Rivett, M.O., Feenstra, S., 2005. Dissolution of an emplaced source of DNAPL in a natura aquifer setting. Environ. Sci. Technol. 39 (2), 447-455.

Rogers, S.W., Ong, S.K., 2000. Influence of porous media, airflow rate, and air channel spacing on benzene NAPL removal during air sparging. Environ. Sci. Tech nol. 34, 764-770. http://dx.doi.org/10.1021/es9901112.

Schnarr, M., Truax, C., Farquhar, G., Hood, E., Gonullu, T., Stickney, B., 1998. Laboratory and controlled field experiments using potassium permanganate to remediate trichloroethylene and perchloroethylene DNAPLs in porous media. J. Contam. Hydrol. 29, 205-224. http://dx.doi.org/10.1016/S0169-7722(97)00012-0.

Schwarzenbach, R.P., Gschwend, P.M., Imboden, D.M., 2002. Environmental Organic Chemistry.

Taylor, T.P., Pennell, K.D., Abriola, L.M., Dane, J.H., 2001. Surfactant enhanced recovery of tetrachloroethylene from a porous medium containing low permeability lenses. J. Contam. Hydrol. 48, 325-350. http://dx.doi.org/10.1016/S0169-7722(00)00185-6.

Thomson, N.R., Fraser, M.J., Lamarche, C., Barker, J.F., Forsey, S.P., 2008. Rebound of a coal tar creosote plume following partial source zone treatment with permanganate. J. Contam. Hydrol. 102, 154-171. http://dx.doi.org/10.1016/j.jconhyd.2008.07.001.

Zhang, C., Yoon, H., Werth, C.J., Valocchi, A.J., Basu, N.B., Jawitz, J.W., 2008. Evaluation of simplified mass transfer models to simulate the impacts of source zone architecture on nonaqueous phase liquid dissolution in heterogeneous porous media. J. Contam. Hydrol. 102, 49-60. http://dx.doi.org/10.1016/j.jconhyd.2008.05.007. 